\title{
Del rito ancestral al rito moderno. En torno a Leopardo al sol de Laura Restrepo
}

Adriana Sara Jastrzębska

Universidad Jagellónica, Cracovia, Polonia

Publicada en 1993, la novela de Laura Restrepo Leopardo al sol constituye uno de los primeros ejemplos de la llamada narconarrativa o narconovela colombiana que tuvo cierta resonancia no solo en el país, sino igualmente en el exterior. "[U]na novela pop con realismo mágico" - la caracteriza José Cardona López, poniendo énfasis en lo que nos interesará en el presente artículo: una particular combinación de lo moderno y lo arcaico en la construcción del mundo representado de la novela, cuyo argumento se concentra en un círculo vicioso de violencias y venganzas entre dos familias poderosas de La Guajira, los Barragán y los Monsalve. ${ }^{1}$ En un arrebato de celos, Nando Barragán mata a su primo Adriano Monsalve, lo que desata el deseo de venganza y lleva a una maldición de violencia que, cada cierto tiempo (los días de zetas), se repite de forma ritual conmemorativa del duelo.

La historia narrada en la novela nace de 11 años de investigación periodística; se inspira en una historia real de la guerra entre los clanes de los Cárdenas y los Valdeblánquez, ocurrida entre los años 70. y los 80. entre Barranquilla y Santa Marta. En 1984 Laura Restrepo, junto con el periodista Fernando Álvarez, publica en la revista Semana el reportaje "La maldición de una estirpe" dedicado a la violencia heredada entre los dos clanes. El tema se vuelve a plantear

1 Cardona López 2000: 384. 
en Semana en 1989, con la publicación de otro reportaje, "Fin de una estirpe", de autor desconocido, en que se narra la guerra en la segunda generación de los varones de las dos familias. Como indica Elicenia Ramírez, se pueden observar correspondencias que claramente demuestran que la autora retomó algunos elementos de la historia real en su novela: la anécdota principal, el perfil de los protagonistas, Nando Barragán y Mani Monsalve, y sus clanes respectivos y, sobre todo, "el marco entocultural de la guerra en la llamada ley guajira".

Muy raramente se lee Leopardo al sol como una narconovela, ya que la realidad del narcotráfico incipiente constituye aquí un telón de fondo en que se desarrolla la historia de los dos clanes rivales. Sin embargo, nos parece muy importante en el corpus de narconarrativas, dado que muestra uno de los contextos culturales cruciales del desarrollo del proceder. En palabras de Ingrith Torres Torres (8-9), la obra:

...muestra el contexto cultural donde se produce este fenómeno que, en el caso de la Guajira, se generó debido al contrabando, actividad cuya historia proviene de la época colonial. En esta novela Restrepo examina, de forma crítica, la construcción de la subjetividad de los individuos, hombres y mujeres, en una sociedad afectada por un narcotráfico incipiente, cuya alteración evidencia el surgimiento de una nueva mentalidad asociada con procesos de una modernización desigual. En esta sociedad no hay una correspondencia entre las políticas gubernamentales, que suponen una nación moderna (educación, salud, equidad, libertad, proyectos culturales y participación ciudadana), y la integración y cohesión social reales con los territorios étnicos y rurales. En cambio, sí hay una amplia posibilidad de acceso a los bienes de la modernización (tecnología, armamento, bienes de consumo, medios de comunicación). ${ }^{3}$

El objetivo del presente artículo es, recurriendo a los ingredientes de la convención y poética narco que presentamos en otras ocasiones ${ }^{4}$, analizar cómo la violencia representada en Leopardo al sol se configura en forma de un particular sincretismo de elementos modernos de una civilización del espectáculo

2 RAMÍREZ VÁSQUEZ 2007: 96-97. Laura Restrepo recibió igualmente una oferta de una cadena de televisión para convertir la historia en guion de telenovela. Esa misma cadena pronto recibió amenazas de los protagonistas de que dinamitarían el estudio de televisión si así se hiciera. Cuando un abogado intercedió por Restrepo, la escritora recibió un mensaje claro: "Que escriba lo que le dé la gana. Que televisión no, porque la ve la gente. Pero que los libros no importan" (citado tras SuÁREZ 2010: 135-136). La anécdota resulta muy interesante a la luz de nuestras reflexiones sobre la dimensión espectacular de la violencia y sus relaciones con el imaginario de la producción audiovisual.

3 TORRES TORRES 2017: 8-9.

${ }^{4}$ Véase p. ej.: JASTRZĘBSKA 2018. 
y elementos arcaicos intrínsecos de mentalidades ancladas en el pensamiento mítico y mágico.

Los ingredientes o componentes de la convención y poética narco en la narrativa colombiana son los siguientes:

1) mundos representados construidos a partir de contrastes, dicotomías y bipolaridades que dan cuenta de las tensiones en el seno de la sociedad y que generaron el narcotráfico.

2) una distorsión antirrealista del protagonista y su entorno a través de hiperbolización o grado variable de mitificación (o desmitificación) en que resuenan ecos del pensamiento primitivo o mítico.

3) participación directa expresada con más frecuencia mediante la primera persona gramatical.

4) incorporación de la oralidad

5) intermedialidad: entroncamiento con otros medios (cine, televisión) y la cultura de masas en general

6) variedad de registros y estilos que permite interpretar la narconovela como enfrentamiento dinámico de paradigmas culturales distintos.

En Leopardo al sol, la construcción del mundo representado se apoya en una dicotomía "fundacional" entre los Barragán y los Monsalve, el eje central del conflicto representado en la novela. Al igual, la configuración temporal de la historia se desdobla entre un tiempo lineal, histórico, en que se desarrolla el conflicto entre los clanes en un entorno urbano y la atemporalidad del mito que impone la celebración ritual repetitiva de actos de violencia. Como las familias representadas en la novela son cultural y étnicamente híbridas, de raíces wayuu, según Ingrith Torres Torres,

[1]a mezcla de razas, junto a la imposición cultural de lo moderno de los centros urbanos, es lo que genera estos sujetos híbridos que terminan por no cumplir las leyes de su raza. Individuos que con sus raíces tribales intentan insertarse en la modernidad, pero el resultado es una mezcla explosiva que lleva a acontecimientos violentos. [...] Esa hibridez se constituye en la metáfora de una modernidad desastrosa y se evidencia una modernidad destructiva, contraria a la sociedad wayuu, donde los aspectos míticos, rituales, de cohesión y de respeto a la palabra son muy importantes. Estos clanes al ser instalados en estos contextos modernos, con lenguajes modernos se dislocan y producen un ámbito muy violento, lo que va a desvirtuar y vaciar de sentido sus tradiciones. ${ }^{5}$

A partir de esto, podemos hablar de una dicotomía cultural inherente al argumento de la novela de Restrepo: una tensión entre la cultura y la sociedad

5 TORRES TORRES 2017: 26-27. Para profundizar el tema de elementos de la cultura wayuu en la novela, véase el trabajo de TORRES TORRES 2017. 
tribal wayuu y la modernidad (imperfecta) de la sociedad colombiana. Elicenia Ramírez Vásquez observa que dicha tensión corresponde a las dos tramas de la novela: la de la venganza y la de las transformaciones de la sociedad tradicional a raíz del narcotráfico, y

[...] la primera pertenece a la realidad atávica, tradicional, e incluso enmarcada en la legitimidad del mito. La segunda se encuentra enmarcada en una realidad histórica moderna y marginal, cargada de tabú, arbitrariedad y de doble moral construida en gran parte desde la informalidad, el chisme, la leyenda, la fragmentación de la memoria colectiva. ${ }^{6}$

En consecuencia, la heterogeneidad estética que puede interpretarse como enfrentamiento dinámico de paradigmas culturales diferentes, resulta el ingrediente dominante de la convención narco en la novela en cuestión, en función del cual se configuran los demás elementos.

De esta manera, en la distorsión antirrealista de los personajes de Leopardo al sol observamos tanto la hipérbole e interpretación literal de metáforas propias del realismo mágico (p.ej. la belleza celestial del jóven Argángel, el olor a perfume omnipresente de Narciso Barragán), como referencias que enmarcan la historia de los dos clanes en el imaginario moderno de la cultura de masas: las telenovelas, películas del oeste, los cómics.

La modernidad aparece en la novela también en la llamativa estética narco de que se rodean Nando Barragán y Mani Mosalve, los dos capos rivales que se disputan la primacía en el tráfico de marihuana en la región y aspiran a lo que Luis A. Astorga llama "lavado social"7. Luis Molina Lora los percibe como personajes-kitsch y observa al respecto:

En suma, una nación como la colombiana, en la que algunos de sus conflictos son retomados en la novela, resulta verosímil que un narcotraficante procure acceder a los favores de clase a través de lo que llamamos una estrategia kitsch. Se incurre en lo cursi mientras se pretende una pertenencia a esa clase en la que algunos de sus miembros se dejan tentar por el dinero fácil que se desprende del negocio con narcóticos así tengan que establecer nexos con personas de una estratificación social considerada inferior, desde una perspectiva clasista. ${ }^{8}$

No obstante, desde el punto de vista de la lectura que proponemos en el presente trabajo, es crucial la propia construcción del relato que maneja tanto

${ }^{6}$ RAMírez VÁSQUEZ 2007: 91.

7 Dice Astorga: "Si con el lavado de dinero, se legitiman fortunas de origen dudoso, con el 'lavado social' se legitiman nombres cuya sola enunciación, en un primer momento, es símbolo de estigma, de temor, de admiración, por la asociación conocida o atribuida socialmente entre quienes los llevan y el tráfico de drogas" (Astorga 1995: 79).

${ }^{8}$ MOLINA Lora 2011: 151. 
la primera persona gramatical, como varios aspectos de participación directa (voces narrativas homo - y heterodiegéticas) e incorporación de la oralidad. La novela tiene una estructura fragmentada, por lo cual varios momentos temporales se presentan con cierto toque de simultaneidad implícita. Laura Restrepo recurre a una polifonía particular: la historia de los Barragán y los Monsalve se desarrolla en el tiempo presente, como si los protagonistas actuaran ante el público que comenta sus acciones y le aporta al lector nuevos conocimientos o rectifica su saber previo. Como veremos a continuación, en un análisis más detallado de los fragmentos iniciales de Leopardo al sol, ya desde el principio se establece en la novela esta línea doble de concebir la violencia: como espectáculo y como rito.

\section{El PARAÍso PERDIDO DE LO ANCESTRAL}

Como se ha explicado, el origen de la guerra fratricida entre las dos familias es el asesinato, en un arrebato de celos, de Adriano Monsalve por su primo Nando Barragán. Este pecado original pone fin a la armónica convivencia de los dos clanes en la comunidad tradicional guajira, donde:

Hasta ahora sus dos familias, los Barragán y los Monsalve, han sobrevivido en el desierto del trueque de carneros y borregos. Al principio de sus tiempos se asentaron juntas en la mitad de un paisaje baldío, de sedimentaciones terciarias y vientos prehistóricos, de montañas de sal y de cal y emanaciones de gas, donde la vida era magra y caía con cuentagotas. Le robaban el agua a las piedras, la leche a las cabras, las cabras a las garras del tigre. Los dos ranchos estaban uno al lado del otro y alrededor no había sino arenas y desolaciones. Como las dos familias eran conservadoras no tenían altercados por política.

Salvo que los niños Monsalve eran verdes y los Barraganes amarillos, no había diferencia entre ellos. Al padre y al tío les decían papá, a la madre y a la tía les decían mamá, a cualquier anciano le decían abuelo, y los adultos, sin hacer distingos entre nietos, hijos o sobrinos, los criaron a todos revueltos, por docenas, en montonera, a punta de voluntad, higos y yuyos secos. ${ }^{9}$

Resulta interesante que el conflicto que pone fin a esta armonía parece resultado de una serie de transgresiones y rompimientos respecto a la cultura ancestral wayuu que demuestran el proceso de la aculturación. En primer lugar, los Barragán y los Monsalve se meten en el negocio de las drogas, dejando las actividades tradicionales de su pueblo. Además, como Nando, borracho

9 Restrepo 2001: 11. 
y celoso, mata a Adriano durante una celebración religiosa del cabo de año; en la pelea trágica de los dos primos vale la pena subrayar el protagonismo del alcohol y cierta falta de respeto del rito católico que como observa Ingrith Torres Torres, no son parte intrínseca de su realidad ni de su cultura. ${ }^{10}$ Parece, pues, que la violencia original es un crimen, pero al mismo tiempo es un castigo por la transgresión y abandono de formas ancestrales de vida.

Ahora bien, en su sueño Nando Barragán, regresa a sus orígenes, al desierto, donde, en palabras de Elicenia Ramírez Vásquez "la actualización del mito de Caín y Abel se realiza dentro del marco de la cosmovisión wayuu". ${ }^{11}$ Tras el viaje de una docena de días y noches, comparada a una vía crucis, llevando el cadáver de su primo al hombro, en una experiencia límite de cuando "el muerto parece vivo y el vivo parece muerto", Nando llega a donde el Tío - "un anciano común y silvestre, con la única particularidad de su avanzadisima edad. Su viajera precolombina castigada por la artritis y la arteriosclerosis.". ${ }^{12}$ En este personaje tanto Ramírez Vásquez, como Torres Torres reconocen a la figura del palabrero tradicional wayuu que ejerce su papel de juez y mediador ${ }^{13}$.

El anciano dictamina la sentencia que, siendo arraigada en la justicia premoderna, tribal, al mismo tiempo significa cierta expulsión de los culpables de la comunidad, un rompimiento definitivo con el mundo ancestral:

- Has derramado sangre de tu sangre. Es el más grave de los pecados mortales. Has desatado la guerra entre hermanos y esa guerra la heredarán tus hijos, y los hijos de tus hijos.

—Es demasiado cruel — protesta Nando- Yo quiero lavar mi culpa por las buenas.

-Entre nosotros la sangre se paga con sangre. Los Monsalve vengarán a su muerto, tú pagarás con tu vida, tus hermanos los Barraganes harán lo propio y la cadena no parará hasta el fin de los tiempos — rabia el anciano encarnizado, fanático, decidido a no ceder ante las súplicas.

- Si voy donde un sacerdote - intenta argumentar Nando-, me bendice y me pone una penitencia en padrenuestros, rosarios, ayunos y azotes. Yo la cumplo y quedo en paz con Dios.

10 TORRES TORRES 2017: 21.

11 RAMírez VÁsQuez 2007: 97.

12 Restrepo 2001: 15.

13 Ramírez VÁsquez 2007: 98; Torres Torres 2017: 16. Dice al respecto Torres Torres 2017: 16 .

La figura del palabrero en la cultura wayuu, incluso hoy, sigue siendo muy importante y valorada. En este espacio geográfico tan apartado, abandonado por los entes estatales, en donde, como ya se mencionó, no hay escuelas, ni educación formal, ni puestos de salud, ni médicos, ni abogados es el palabrero, representado por el tío materno, quien actúa como jefe y guía del clan, y ejerce su rol de mediador frente la necesidad de establecer acuerdos de convivencia ante las afrentas, robos, asesinatos y demás comportamientos considerados no deseados para la sociedad. 
- No hay cura que valga ni bendición que sirva. Por aquí no viene la Iglesia desde los tiempos de Pablo VI, que pasó volando en un avión hacia el Japón y nos hizo adiós con la mano. Ésta es una tierra sin Dios ni evangelios, aquí sólo vale lo que dijeron los ancestros.

-Puedo buscar un juez que me juzgue y me aprisione. Pago mis años de condena y vuelvo a la libertad, en paz con los hombres.

- Hasta acá no llega juez, ni abogado, ni tribunal. Ésos son lujos de extranjeros. Nuestra única ley es la que escribe el viento en la arena y nuestra única justicia es la que se cobra por la propia mano.

Las cosas siempre han sido y serán tal como las dice el Tío, viejo profeta dueño de verdades y experto en fatalismos, y Nando Barragán se rinde ante la evidencia milenaria, abrumadora. ${ }^{14}$

En el fragmento citado vemos claramente un enfrentamiento de dos sistemas de entender la justicia: Nando propone recurrir a la justicia moderna, castigo de prisión y penitencia, lo que resulta imposible a la luz de la tradición ancestral de su pueblo y las leyes de su tierra. El Tío no solo precisa las condiciones y circunstancias de ejercer la venganza,

Si matas a tu enemigo, deberás hacerlo con tu propia mano; nadie podrá hacerlo por ti. La pelea será de hombre a hombre, y no por encargo. No debes herirlo si está desarmado o descuidado, ni sorprenderlo por detrás, ${ }^{15}$

sino también expulsa a las dos familias del desierto, poniendo fin a su existencia en el mundo tribal; los Barragán y los Monsalve tienen que establecerse, respectivamente, en la ciudad y en el puerto, trasladando sus leyes de honor ancestrales al mundo moderno.

\section{Observa al respecto Elicenia Ramírez Vásquez:}

...entendemos entonces que un sentido de realidad incuestionable finalmente es trastocado por la influencia de las economías ilegales, quienes terminan por desvirtuar y vaciar de sentido a las formas tradicionales, fundamentadas en el honor y la palabra. La salida del territorio ancestral hacia la ciudad señala el primer rompimiento, luego la excentricidad, el lujo, el culto al objeto y al dinero determinan nuevos valores que justifican la vinculación del sicario, el cual termina por instaurar un nuevo ethos que impone la lógica de la arbitrariedad y el caos. Los motivos de la vieja confrontación son desbordados por la nueva realidad del narcotráfico, en la que la guerra no tiene ni reglas ni límites. ${ }^{16}$

A partir de aquí, el rito ancestral de la venganza se enfrentará -y chocará - con la lógica de la violencia moderna narco, concebida como espectáculo.

\footnotetext{
14 Restrepo 2001: 16.

15 Restrepo 2001: 16.

16 Ramírez VÁsquez 2007: 102.
} 


\section{EL ESPECTÁCULO POP DE LA VIOLENCIA}

La escena que abre la novela transcurre en un bar donde Nando Barragán habla con su amada Milena.

Ese que está ahí, sentado con la rubia. Ése es Nando Barragán.

Por la penumbra del bar se riega el chisme. Ese es. Nando Barragán. Cien ojos lo

miran con disimulo, cincuenta bocas lo nombran en voz baja.

-Ahí está: es uno de ellos.

Dondequiera que van los Barraganes los sigue el murmullo. La maldición entre

dientes, la admiración secreta, el rencor soterrado. Viven en vitrina. No son lo que son

sino lo que la gente cuenta, opina, se imagina de ellos. Mito vivo, leyenda presente, se

han vuelto sacos de palabras de tanto que los mientan. Su vida no es suya, es de

dominio público. Los odian, los adulan, los repudian, los imitan. Eso según. Pero todos, por parejo, les temen. ${ }^{17}$

Ya desde esta primera escena, se nota de manera muy clara que al protagonista se lo introduce como un actor en el escenario de un teatro; el público nota su aparición, lo indica, lo presenta y éste empieza a actuar. Como en el pensamiento berkeleyano, la existencia de Nando y los demás Barraganes depende de ser percibidos; existen, ya que son mirados. Tal situación enunciativa introduce desde el principio de la novela cierto toque de teatralidad en la representación de la historia de los clanes; teatralidad que pronto se verá combinada con el imaginario propio de la cultura audiovisual, cuando los Monsalve llegan a ejecutar la venganza y el público los percibe como a personajes de ficciones populares:

El Mani grita: Nando Barragán, vengo a matarte, porque tú mataste a mi hermano,

Adriano Monsalve, y la sangre se paga con sangre. Y grita también: Hoy cumple veinte

años esa afrenta. Y Nando le advierte: Estoy desarmado, y el Mani le dice: Saca tu

arma, para que nos enfrentemos como hombres.

-Eso parece un cómics, una de vaqueros. ¿Y qué respondió Nando? ¿Cáspita?

17 Restrepo 2001: 5. 
¿Recórcholis? ¿Pardiez? Qué va. Esa gente no decía nada, no advertía nada. No se ponían con primores: disparaban y ya. ${ }^{18}$

El imaginario de la cultura pop desempeña un papel clave en la visión de la vida de las dos familias que se interpreta en términos ficcionales en dos sentidos: por un lado, adquieren una dimensión legendaria por su violencia, su poder y el temor que despiertan, por el otro - llegan a ser objeto de envidia por la dimensión espectacular de su lifestyle. Lo vemos por ejemplo en este fragmento:

Una luna ligera respira dulcemente sobre la noche del puerto. Las olas negras del

mar son mamíferos pesados y dóciles que se acercan en manada a lamer los cimientos

de la gran casa. La terraza iluminada levita sobre el agua, como un ovni, $y$ en una de sus esquinas se resguarda de la brisa una mesa íntima, con dos puestos, mantel de lino

blanco, copas de cristal, vaso con rosas. Nelson Ned canta una canción romántica por el

estéreo de fidelidad cuadrafónica y se esparce sedosa su voz nasal de enano enamorado.

-Parecía escenario de telenovela.

No parece. Es. La vida de ellos es pura telenovela. Por lo menos adentro de la

casa, porque afuera la película es de terror, con reflectores potentes para vigilar los

alrededores, circuito cerrado de televisión para delatar al que se acerque, toses de

guardaespaldas que pasan haciendo la ronda y sombras de perros adiestrados para matar. ${ }^{19}$

Vemos aquí claramente cierta fascinación por el estilo de vida de los mafiosos y cierta identificación del mismo con el mundo de las ficciones cinematográficas y televisivas. Además de alusiones al cine y la televisión, son muy numerosas en la novela las referencias al mundo de celebrities; se mencionan actores, deportistas y otras figuras conocidas del mundo mediático. Igualmente las marcas (coca-cola, Ray-Ban, Lincoln Continental, Nike etc.) se evocan como símbolo de éxito en el mundo de consumo y parte integrante del imaginario popular. Son elementos de la llamada narcocultura o subcultura de las drogas, basada en la imagen, ampliamente difundida por los medios audiovisuales y devenida, ella misma, una suerte de espectáculo.

\footnotetext{
18 Restrepo 2001: 8.

19 Restrepo 2001: 19.
} 
El pueblo, los vecinos de las dos familias y testigos de la guerra también contribuyen a reforzar la espectacularidad de la violencia, cuando parecen divertirse con las matanzas de los Barragán y los Monsalve y se apuestan quién va a ser la víctima siguiente. ${ }^{20} \mathrm{O}$ cuando crean una suerte de museo de la guerra fratricida, reconociéndola como su orgullo y una parte de su identidad:

Muchos eran los estragos que a lo largo de los años iba dejando ese pleito. No quedaba ya cuadra sin su propia historia de sangre. Eran tan frecuentes los tiroteos, que nosotros mismos, a nuestro propio barrio, el lugar donde habíamos nacido y donde forzosamente teníamos que crecer, le decíamos La Esquina de la Candela. Los de los otros barrios le decían así también.

Entre la muchachada era diversión contarles a los visitantes los distintos episodios de esa guerra. Como en todos los oficios, entre los narradores había unos mejores que otros: los que le ponían color y detalle al relato, los de más memoria, los que imitaban bien el ruido de ráfagas de metralleta y de chirrido de llantas. O los que sabían actuar en cámara lenta los golpes de balas en un cuerpo, o una escena de lucha a patadas, o a cuchillo.

Los visitantes quedaban impresionados con todo lo que oían. Y veían, porque les organizábamos visitas, como en los museos, llevándolos a los distintos escenarios: aquí asesinaron a un Barragán cuando salía del entierro de un hermano, les contábamos, y ellos podían meter el dedo en los orificios de bala en la pared del cementerio. O estos cristales quedaron destrozados cuando el atentado contra fulano, o en esta lavandería se encontraba tal cuando le dieron el tiro en tal lado. Nuestro barrio, que antes era común y corriente, simplemente uno de tantos, ahora tenía su tradición, su folclor. ${ }^{21}$

De esta manera, paralelamente a los Barragán y los Monsalve que existen porque tienen el público que los observa, la razón de ser de este público parece ser observadores, testigos, audiencia aficionada al espectáculo de actos violentos en una suerte de relación simbiótica. Las dos familias montan el espectáculo, pero es el público que decide sobre su forma -estética y ética - definitiva. Fijémonos que en el coro que consitutye la voz narrativa principal, surgen preguntas, indagaciones que no son sino curiosidad morbosa por los detalles de asesinato y torturas:

- ¿Con qué lo asesinaron, con arma blanca, o con arma de fuego?

- Lo asesinaron con saña: a balazos y después a cuchillo. ${ }^{22}$

\footnotetext{
20 Restrepo 2001: 41.

${ }^{21}$ RESTREPO 2001: 47-48.

${ }^{22}$ Restrepo 2001: 133.
} 
A partir de los comentarios del coro, de la información fragmentaria, distorsionada, complementada y rectificada varias veces, se configura una imagen incierta, borrosa, medio-irreal/medio-ficcional de la guerra entre los clanes; una imagen apoyada en una serie de reiterados "se dice que", "cuentan que", "quizá" "quién sabe" "a lo mejor".

Como subraya Francoise Bouvet al reflexionar sobre el papel de la sociedad en la creación de la imagen monstruosa de los protagonistas: "Y poco a poco se va insinuando la idea de que la sociedad participa en la creación de monstruos: ¿realmente son monstruosos Nando, Mani y las Barraganes, o así los quieren presentar, conscientemente o no, aquellos que los rodean?"23

\section{LA VENGANZA DE LAS VENGANZAS}

Los dos conceptos de violencia - la antigua y la moderna - confluyen a su vez en la escena casi final de la novela, cuando, durante las celebraciones del carnaval, muere (según las voces del coro, antes de ser matado) Nando Barragán. Configurada ya de por sí como espacio de espectáculo, la ciudad llena de gente disfrazada, de fiesta, llega a ser escenario en que la percepción mítica de la Muerte inminente del legendario Nando Barragán se observa junto con la celebración popular de la muerte del que, durante años, aterrorizaba el pueblo.

El fragmento citado -recordemos que la escena transcurre durante la parranda del Carnaval - muestra muy bien la tensión, la ambigüedad y confusión entre el mito y el espectáculo:

Nando queda absorto en el barrizal de confeti y festones pisoteados, con la cabeza empalagada por una melcocha de pensamientos sin concierto, consistencia ni color.

Por la calle baja bailando la Muerte, solitaria. No es una muerte imponente, de poderosa presencia y lujoso disfraz, sino un pobre esqueleto improvisado y flaco, de calavera de palo, sábana vieja por capa y gran hueso pelado de animal en la mano. Los vecinos le sacan el cuerpo, se encierran en sus casas para que siga de largo, la espían por las ventanas entreabiertas y comentan que nunca vieron una muertecita tan insignificante y asquerosa: maldita, traicionera y sin grandeza, demasiado igual a la muerte de verdad. Ella se adueña de la calle desierta y reparte vejigazos al vacío. Azota el aire con insidia, pero sin fuerza y sin ton ni son. - ¿Y descubrió a Nando, acurrucado en el escalón?

- No, no lo vio, o hizo como si no lo viera, y se puso a silbar una canción extranjera, muy desafinada. Nando en cambio la miró de frente, con

${ }^{23}$ Bouvet 2014: 31. 
criterio de conocedor. Se había topado con la muerte tantas veces que enseguida distinguía la verdadera de las de imitación. Ésta no vale la pena, pensó, y la dejó pasar. ${ }^{24}$

El círculo vicioso de las muertes y venganzas entre los Barragán y los Monsalve lleva a una venganza definitiva, la ejercida por el pueblo enmascarado, luego anónimo, en el cadáver de Nando. En el acto de profanación igualmente confluyen la lógica del rito mágico premoderno y la del espectáculo de la violencia:

Sucedió que las falsas Marimondas no se contentaron con matarlo sino que además arrastraron su cadáver por las calles del barrio, a manera de escarmiento y de celebración. Las gentes corrieron a mirarlo: lo tocaron, le arrancaron la ropa y lo reconocieron. A nadie le cupo duda: era irrefutablemente él, y la evidencia de su muerte fue pesada y desnuda como el propio cadáver.

- ¿Alguien se compadeció del difunto?

- No hubo solidaridad con él, y a lo mejor tampoco hubo lástima. Si alguno se compadeció, prefirió callar por no desafiar a la masa enardecida de vecinos, que por fin cobraba su mejor venganza. Una venganza colectiva inconscientemente tramada durante cada una de las noches que tuvimos que permanecer encerrados en nuestras casas, detrás de candados y trancas, con los niños despiertos y aterrorizados, mientras afuera, en la calle, los Barragán repartían candela y hacían tronar el tiroteo. Por eso la hora de la muerte fue también la del desquite y cundió la ley del ojo por ojo. El temor que le tuvimos en vida cambió de signo y se volvió agresión en cantidad proporcional: los más sometidos antes, se ensañaron más después. Queríamos arrancarle un pelo por cada uno de los miedos que nos había hecho pasar; un diente por cada angustia; por cada muerto un dedo; los dos ojos por la sangre derramada; la cabeza por la paz perdida; las entrañas por toda la deshonra que nos había hecho tragar. Queríamos quitarle la vida que ya no tenía a cambio del futuro cagado que nos llegaba, y lo repudiamos para siempre, porque nos había estampado el sello de la muerte en la cara. ${ }^{25}$

Esta escena - que de hecho cierra la novela - concluye la condena de los dos clanes, pero al mismo tiempo pone de manifiesto el carácter inherente de actitudes violentas en la sociedad marcada por el narcotráfico. En palabras de Francoise Bouvet:

Nando es el rey del carnaval, este chivo expiatorio burlado que describen el antropólogo Frazer o el crítico literario Bajtín, y que al morir, libera la sociedad. Es el Edipo considerado como responsable de la propagación

${ }^{24}$ Restrepo 2001: 167-168.

25 RESTREPO 2001: 168-169. 
de esta peste que es la violencia: el pueblo incapaz de luchar contra ella, se lanza a una caza desesperada del culpable por excelencia, creyendo así salvarse de un mal que sin darse cuenta va reproduciendo. Pero más allá de su aspecto catártico, este episodio de barbaridad colectiva paroxística viene a confirmar que el ser humano, por naturaleza, es un monstruo de violencia. ${ }^{26}$

Respecto a este ajuste de cuentas colectivo, violento y medio-irreal por el ambiente carnavalesco dominante, la investigadora observa que

Esta reproducción monstruosa y colectiva de la violencia también echa raíces en la estructura y el funcionamiento de la sociedad. Precisamente la sociedad de Leopardo al sol, sometida a una ley de silencio que para Pécaut simboliza la ruptura de los lazos colectivos en las zonas de violencia, parece volver a la vida y recobrar habla y unidad gracias a la violencia. Se abre una nueva era, tan monstruosa como la precedente, lo que inquieta pero no sorprende realmente. ${ }^{27}$

\section{Conclusión}

La novela Leopardo al sol propone una lectura sociocultural del impacto de las economías ilegales del narcotráfico en la sociedad tradicional. Según Elicenia Ramírez Vásquez,

Asistimos al drama del desarraigo y la pérdida de la identidad, debido a la asimilación de dinámicas económicas viciadas que modificaron las conductas y la idiosincrasia del pueblo guajiro, convirtiéndole en paria una vez que el dinero del contrabando y el narcotráfico le impone una realidad que le es ajena. ${ }^{28}$

Desde la perspectiva de elementos de la convención y poética narco, la obra se fundamenta en dicotomías y bipolaridades esenciales no solo a nivel individual de dos clanes enfrentados, sino igualmente - o sobre todo - entre dos mundos enfrentados: el de la tradición cultural wayuu y el de la modernidad. La violencia que se narra en la novela combina rasgos propios de dos sistemas axiológicos y éticos: el ancestral y el de la narcocultura que en nuestro análisis corresponden a la lógica, respectivamente, del mito y del espectáculo. Estos dos paradigmas culturales se enfrentan de manera dinámica, mostrando las

\footnotetext{
${ }^{26}$ Bouvet 2014: 28.

27 Bouvet 2014: 29.

${ }^{28}$ RAMÍREZ VÁSQUeZ 2007: 105.
} 
consecuencias de aculturación y la modernización incompleta e imperfecta de la mentalidad de los personajes.

El elemento crucial de la construcción narrativa de Leopardo al sol es el coro caribeño que resuena, sin previo aviso, en los párrafos de la narración; un coro compuesto de voces de los testigos, observadores, habitantes del pueblo, o del público, la audiencia que, emocionada, mira el espectáculo. Son voces que comentan, indagan, manejan informaciones fragmentarias, expresan sus dudas, sus emociones y sus opiniones. Desde el punto de vista de un enfrentamiento de paradigmas culturales propio de la narconovela, podemos reconocer en el coro caribeño los ecos del coro del teatro antiguo griego o la voz de un hablador responsable de conservar en su memoria y transmitir oralmente los momentos claves de la historia de su pueblo, pero al mismo tiempo podemos interpretarlos -en clave audiovisual - como voces de quienes miran y comentan una telenovela o un reality-show o incluso, podemos ver aquí una suerte de meta-espectáculo, como el formato Gogglebox..$^{29} \mathrm{El}$ pensamiento mítico y el pensamiento propio de la cultura basada en la imagen, audiovisual, se interpenetran retratando a la perfección la naturaleza paradójica - arcaica e hipermoderna a la vez - de la narcocultura.

Terminemos con la interpretación propuesta por Elicenia Ramirez Vásquez, según la que este conjunto de voces y la configuración narrativa de la historia narrada en la novela de Restrepo, demuestran que

la violencia se acepta como una realidad inamovible, como un dogma, como una epidemia que nos convierte en víctimas y a su vez en victimarios, en transmisores del virus mortal. Esa convivencia con la violencia crea una atmósfera de irrealidad expresada por las voces de la colectividad, las cuales hablan desde una percepción que finalmente crea una leyenda. Este relato colectivo permite que se tome distancia para ver reflejado allí nuestra tragedia, pues la tara de la violencia parece definirnos y permanentemente lo legitimamos como una tradición, como parte de nuestro folclor, pero sobre todo como una entidad que está por encima de nosotros y sobre la cual no podemos hacer nada, sólo aceptarlo como una verdad irrefutable. ${ }^{30}$

29 Donde el espectáculo televisivo consiste en observar a la gente que mira la televisión, comentado, indagando, dando sus opiniones - como lo hacen las voces del coro en la novela analizada.

${ }^{30}$ Ramírez VÁSQuez 2007: 106. 


\section{Bibliografía}

Astorga 1995 - L. A. Astorga, (1995), Mitología del "narcotraficante" en México. México, Plaza y Valdés 1995.

Bouvet 2014 - F. Bouvet, "Leopardo al sol: la monstruosidad desvelada de la Colombia del narcotráfico." Amerika. Mémoires, identités, territoires, n.11, 2014.

CARdona LóPez 2000 - J. Cardona Lopez "Literatura y narcotráfico: Laura Restrepo, Fernando Vallejo, Darío Jaramillo Agudelo”. En: M. M. Jaramillo, B. Osorio y A. Robledo (comps.) Narrativa y cultura. Literatura colombiana del siglo XX, Bogotá, Ministerio de Cultura, 2000, pp. 378-406

JASTRZĘBSKA 2018 - A.S. Jastrzębska, "Una literatura cómplice. Convención y poética narco en Comandante Paraíso de Gustavo Álvarez Gardeazábal." Studia Iberystyczne, n. 17: 177-194, 2018.

Molina Lora 2011 - L. E. Molina Lora, Narrativa de drogas: una investigación transatlántica en la producción cultural de España, México y Colombia. Diss. Université d'Ottawa/University of Ottawa, 2011.

RAmírez VÁsQuez 2007 - E. Ramírez Vásquez, "Entre el mito y la historia Una reflexión sobre la violencia en la novela Leopardo al sol de Laura Restrepo". Estudios de literatura colombiana, n. 21: 93-107, 2007. Restrepo 2001 [1993] - L. Restrepo, Leopardo al sol, Barcelona, Anagrama 2001.

SuÁrez 2010 - J. Suárez, Sitios de contienda: producción cultural colombiana y el discurso de la violencia, Madrid: Iberoamericana Vervuert, 2010.

TORRes TORRES 2017 - I. Torres Torres, Leopardo al sol: la fuerza de lo ancestral femenino. Diss. Pontificia Universidad Javeriana, 2017.

\section{Summary \\ From the ancestral rite to the modern rite. Around Leopardo al sol by Lau- ra Restrepo}

This article proposes an analysis of Laura Restrepo's Leopardo al sol (1993), a novel that proposes a sociocultural interpretation of the impact of the illegal economies of drug trafficking on traditional society. By analyzing the ingredients of the convention and poetics narco in the text, we observe how the violence represented in Leopardo al sol takes the form of a particular syncretism of 
modern elements of a civilization of spectacle and archaic elements intrinsic to mentalities anchored in mythical and magical thinking.

Keywords: Laura Restrepo, Colombian Fiction, narco, ritual, violence

\section{Streszczenie}

Od rytu przodków do rytu nowoczesnego. Wokół Leopardo al sol Laury Restrepo

Niniejszy artykuł omawia powieść Laury Restrepo Leopardo al sol (1993), która proponuje socjokulturową interpretację wpływu narkobiznesu na tradycyjne społeczeństwo. Analizując obecne w utworze poszczególne elementy konwencji i poetyki narco, obserwujemy, że przemoc przedstawiona w Leopardo al sol wykazuje cechy swoistego synkretyzmu, łącząc elementów nowoczesnej cywilizacji spektaklu z elementami archaicznymi, nieodłącznie związanymi z mentalnością zakorzenioną w myśleniu mitycznym i magicznym.

Słowa kluczowe: Kolumbia, Laura Restrepo, narkopowieść, rytuał, przemoc 